\title{
PRÉ-DIMENSIONAMENTO E MODELAÇÃO DE TANQUES HIDROPNEUMÁTICOS
}

\author{
Gustavo D. Lessa*, Edevar L. Junior, Daniel A. Sierra
}

\section{Resumo}

Em sistemas de condução de fluídos, o tipo de escoamento pode variar juntamente com a realização de manobras frequentes, como fechamento de válvulas e registros, ou por eventos imprevistos como paradas súbitas de bombas. Estas manobras (ou eventos) geram o chamado escoamento transitório, o qual pode ser muito nocivo para as instalações por gerar ondas muito fortes de pressão. O tanque hidropneumático (TH) é o modo mais eficiente de amortecer os efeitos do escoamento transitório, pois, ao contrário de outros equipamentos, ele pode atenuar tanto pressões máximas quanto mínimas, além de não requerer muito espaço para ser instalado. Dessa forma, este trabalho visa estudar mais a fundo algumas metodologias e parâmetros do pré-dimensionamento desses dispositivos e modelálos em software (Hammer) para entender melhor seu funcionamento na prática, além de compor um banco de dados para o futuro treinamento, em etapas posteriores, de uma rede neural.

\section{Palavras-chave:}

\section{Escoamento Transitório, Tanque Hidropneumático, Modelação Hidráulica.}

\section{Introdução}

Apesar de existirem várias metodologias propostas para o pré-dimensionamento dos tanques, somente duas foram selecionadas para serem modeladas, sendo elas, Vibert (1950) e Graze \& Forrest (1974). Estes dois estudos foram selecionados pois apresentam grandes diferenças em seus métodos. Enquanto Graze considera a perda de carga por atrito e permite a escolha do índice politrópico (n), Vibert negligencia o atrito e trabalha com o comportamento isotérmico dos gases, proporcionando uma solução inicial (volume do TH) como um método mais simples e direto.

Inicialmente os tanques foram prédimensionados seguindo os parâmetros da adutora de Macintyre (1987), mas, depois, tiveram seus valores de comprimento, desnível entre reservatórios e diâmetro alterados para que fosse analisado mais a fundo como as metodologias se comportam. Em fase posterior, os tanques foram modelados e tiveram alterados os valores de índice $n$ e perda de carga por atrito na entrada (k), para que que ficasse evidente a influência destes parâmetros no amortecimento das ondas.

\section{Resultados e Discussão}

A modelagem em software foi feita a partir de diversos volumes de tanques conseguidos a partir das metodologias selecionadas. Dessa forma, com os dados obtidos do Hammer, pode-se plotar gráficos de volume de ar no tempo variando os coeficientes $\mathrm{n}$ e $\mathrm{k}$.

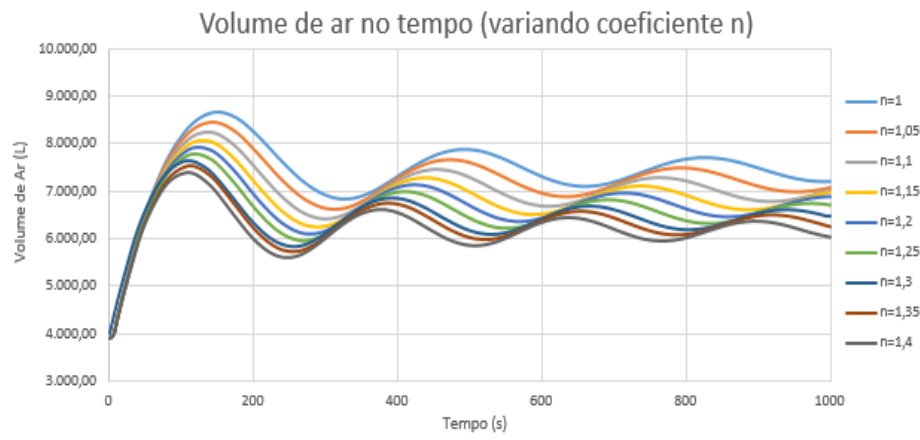

Figura 1. Volume de ar no tempo variando $n$

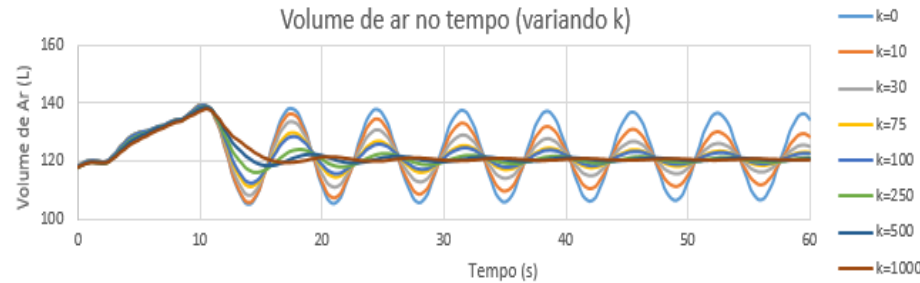

Figura 2. Volume de ar no tempo variando k.

\section{Conclusões}

O índice politrópico (n) e o coeficiente de perda de carga por atrito na entrada $(k)$ influenciam no volume do tanque. Quando o n é mínimo $(1,0)$ o ar dentro do dispositivo tem comportamento isotérmico, dessa forma, todo o calor gerado na compressão é dissipado fazendo com que o volume da expansão seja grande. Entretanto, para o n máximo $(1,4)$, o gás tem comportamento adiabático, armazenando toda a energia gerada na compressão fazendo com que o volume da expansão seja menor. Dessa forma, o $\mathrm{n}$ pode ser usado como um dos fatores para limitar o volume do $\mathrm{TH}$, sendo que ao considerar um comportamento isotérmico o amortecimento é menor, e caso contrário (adiabático) é maior, aumentando e diminuindo, respectivamente, o tamanho do dispositivo. Na literatura se recomenda o uso de um valor intermédio, $n=1.2$. Já o $\mathrm{k}$, se mostrou um fator ainda mais relevante sendo que para coeficientes menores o volume de gás não foi estabilizado dentro do intervalo de tempo apresentado, demonstrando que as pressões ainda não foram amortecidas e 0 tanque permanece trabalhando. Entretanto, para ks maiores, o volume de gás rapidamente se estabiliza e a atenuação das ondas é muito mais rápida abrindo a possibilidade para a redução do volume do $\mathrm{TH}$.

\section{Agradecimentos}

Ao programa CNPq/PBIC e à FEC-UNICAMP no âmbito do Departamento de Recursos Hídricos.

1 VIBERT, M., A Proteção de Tubulações Contra os Surtos de Pressão (Tradução livre do artigo de Vibert), 1949.

${ }^{2}$ GRAZE, H. R. \& FORREST, J. A., New Desing Charts For Air Chambers, University of Canterburry, New Zealand, 1974. 